\title{
A Corpora-Based Analysis of the Collocations of May as Well and Might as Well
}

\author{
Namkil Kang \\ Far East University, Chungbuk, South Korea
}

\begin{abstract}
The goal of this paper is to compare the collocations of May as well and Might as well and to provide an in-depth analysis of the frequency of each expression in the Corpus of Contemporary American English (3 July. 2021. Online https://corpus.byu.edu/coca), the British National Corpus (3 July. 2021. Online https://corpus.byu.edu/bnc), and the Corpus of Historical American English (3 July. 2021. Online. https://corpus.byu.edu/coha). With respect to the COCA (3 July. 2021. Online https://corpus.byu.edu/coca), it is interesting to note that May as well go is the most preferred by Americans, followed by May as well get, and May as well give, in descending order. It is also interesting to point out that Might as well get is the most preferred by Americans, followed by Might as well go, and Might as well make, in descending order. With respect to the BNC (3 July. 2021. Online https://corpus.byu.edu/bnc), it is noteworthy that the collocation May as well go is the most preferred by the British, followed by May as well tell (May as well get), May as well make, and May as well use, in descending order. It is also worth noting that Might as well go is the most preferable among the British, followed by Might as well get, Might as well make (Might as well take), and Might as well give, in descending order. Finally, this paper argues that Might as well is preferred over May as well by both Americans and the British and that the former is slightly different from May as well in its use.
\end{abstract}

Index Terms-COCA, BNC, COHA, may as well, might as well

\section{INTRODUCTION}

The corpus is a database of millions of words that can be studied to show how language works. The main purpose of this paper is to compare the collocations May as well and Might as well and to provide a frequency analysis of each expression in the Corpus of Contemporary American English (3 July. 2021. Online https://corpus.byu.edu/coca)), the British National Corpus (3 July. 2021. Online https://corpus.byu.edu/bnc), and the Corpus of Historical American English (3 July. 2021. Online. https://corpus.byu.edu/coha). The collocation types May as well and Might as well are synonymously used, but they are slightly different from each other in their use and preference. This paper aims to consider which type is preferred by Americans and the British. We also aim to consider the genre frequency of the types May as well and Might as well in the COCA (3 July. 2021. Online https://corpus.byu.edu/coca) and BNC (3 July. 2021. Online https://corpus.byu.edu/bnc). Additionally, we examine which type was preferred by Americans from 1820 to 2010. We examine when the types May as well and Might as well were the most preferable among Americans, as well as when each was considered the least desired. Also, we examine the collocations May as well and Might as well in the COCA (3 July. 2021. Online https://corpus.byu.edu/coca) and BNC (3 July. 2021. Online https://corpus.byu.edu/bnc). We consider which verb phrase is the most frequently used along with the types May as well and Might as well in the COCA (3 July. 2021. Online https://corpus.byu.edu/coca) and BNC (3 July. 2021. Online https://corpus.byu.edu/bnc). By using the software NetMiner, we try to visualize the collocations of May as well and Might as well in the COCA (3 July. 2021. Online https://corpus.byu.edu/coca) and BNC (3 July. 2021. Online https://corpus.byu.edu/bnc). The organization of this paper is as follows. In section 2.1, we argue that just as in the case of May as well, Might as well is the most widely used expression in the TV/movie genre. In Section 2.2, we contend that May as well and Might as well are the most widely used in the fiction genre of the BNC (3 July. 2021. Online https://corpus.byu.edu/bnc). From this, it is clear that British writers most prefer May as well and Might as well. It should be noted, however, that Might as well may be preferred over May as well by the British. In section 2.3, we maintain that the frequency of Might as well is three times higher than that of May as well. This in turn indicates that Might as well may be preferred over May as well by Americans. In section 3.1, we argue that May as well go is the most preferred by Americans, followed by May as well get, May as well give, May as well take, May as well try, May as well make, and May as well start, in descending order. We further argue, on the other hand, that Might as well get is the most preferred by Americans, followed by Might as well go, Might as well make, Might as well take, Might as well give, Might as well start, Might as well try, Might as well say, and Might as well tell, in descending order. In section 3.2, we maintain that May as well go is the most preferable among the British, followed by May as well tell (May as well get), May as well make, May as well use, May as well sit (May as well give), and May as well call, in descending order. We also maintain that Might as well go is the most preferred by the British, followed by Might as well get, Might as well make (Might as well take), Might as well give, Might as well put, Might as well try, and Might as well say, in descending order. Finally, we contend that Might as well is slightly different from May as well in its use and preference. 


\section{A Frequency AnALYSiS of MaYAS WELL AND Might AS WELL}

\section{A. The Genre Frequency of May as Well and Might as Well in the COCA}

In this section, we aim to examine the frequency of May as well and Might as well in eight genres. We compare the frequency of May as well and that of Might as well in the COCA (1990-2019 (3 July. 2021. Online https://corpus.byu.edu/coca)). Table 1 indicates the genre frequency of May as well and Might as well in the COCA (3 July. 2021. Online https://corpus.byu.edu/coca):

TABLE 1

GENRE FREQUENCY OF MAY AS WELL AND MIGHT AS WELL IN THE COCA

\begin{tabular}{|l|l|l|l|l|l|l|l|l|l|l|}
\hline Genre & ALL & BLOG & WEB & TV/M & SPOK & FIC & MAG & NEWS & ACAD \\
\hline $\begin{array}{l}\text { May as } \\
\text { well }\end{array}$ & 1,809 & 382 & 312 & 385 & 102 & 330 & 161 & 93 & 44 \\
\hline $\begin{array}{l}\text { Might } \\
\text { as well }\end{array}$ & 10,518 & 1,498 & 1,150 & 2,670 & 762 & 2,663 & 916 & 697 & 162 \\
\hline
\end{tabular}

An important question that naturally arises is "Which type is preferred by Americans?" Table 1 clearly indicates that Might as well is preferable to May as well in America. The overall frequency of May as well is 1,809 tokens, whereas that of Might as well is 10,518 tokens. This implies that the type Might as well may be preferred over the type May as well by Americans. As indicated by Murphy (2016) (Murphy, R. (2016). Grammar in Use. Cambridge University Press. Singapore) and Murphy (2019) (Murphy, R. (2019). English Grammar in Use. Cambridge University Press. New York), Might as well do something means that one should do something because there is no better alternative. There is no reason not to do something. We can also use May as well instead of Might as well. This indicates that May as well and Might as well are synonymously used. However, by demonstrating the use of May as well and Might as well in eight genres, we attempt to specify that they are slightly different from each other in preference and use.

An immediate question is "In which genre is May as well the most frequently used?" Table 1 clearly shows that the type May as well is the most widely used in the TV/movie genre. This implies that American celebrities most prefer May as well in the TV/movie genre of eight genres. Note, however, that the type Might as well may be preferred over May as well in the TV/movie genre. This indicates that May as well is the most frequently used in the TV/movie genre, but it is less preferred to Might as well.

It is interesting to note that the type May as well is the second most preferred collocation in the blog genre. A blog is an online journal where bloggers write about their hobbies and experiences. That May as well ranks second in the blog genre suggests that American bloggers prefer using the type May as well. Note, however, that the type Might as well may be preferred over the type May as well by American bloggers. Specifically, the frequency of May as well in the blog genre is 382 tokens, whereas that of Might as well is 1,498 tokens. That is, the frequency of Might as well is ten times higher than that of May as well. This implies that American bloggers prefer using Might as well to using May as well.

It is interesting to note that May as well is the third most preferred expression in the fiction genre. The frequency of May as well is not low compared with that of May as well in the TV/movie genre. This suggests that American writers are fond of using the type May as well in their novels. It should be noted, however, that the type Might as well may be preferred over the type May as well by American writers. The frequency of Might as well is eight times higher than that of May as well. This implies that the type Might as well is favored over the type May as well in the fiction genre.

It is also worth noting that the type May as well ranks sixth in the spoken genre. The frequency of May as well in the spoken genre is three times lower than that of Might as well. From this, it is clear that the type May as well is not as frequently used in the spoken genre. However, this does not mean that Americans do not prefer using this type in the spoken genre. However, it should be noted that the type Might as well may be preferred over the type May as well in the spoken genre. The frequency of Might as well is seven times higher than that of May as well. This indicates that Americans prefer using Might as well to using May as well in daily conversation.

The frequency of Might as well will now be explored. An important question is "In which genre is Might as well the most commonly used?" Table 1 clearly indicates that just as in the case of May as well, Might as well is the most widely used collocation in the TV/movie genre. It can be inferred from this that American celebrities prefer using Might as well in the TV/movie genre. Moreover, it is reasonable to assume that American celebrities prefer using Might as well to using May as well in the TV/movie genres as the frequency of the former is higher than that of the latter. It is worth noting that Might as well is the second most preferred in the fiction genre. Note that May as well is the second most preferred in the blog genre. Clearly, this indicates that the use of the type Might as well is slightly different from that of May as well.

Might as well is the third most preferred one in the blog genre. Notice that May as well is the second most preferred in the blog genre. This indicates that May as well is slightly different from Might as well in its use. In addition, the frequency of Might as well is three times higher than that of May as well in the blog genre. Thus, it is reasonable to assume that Might as well may be preferred over May as well by American bloggers. From this, it is clear that Might as well is slightly different from May as well in its use and preference. 
Might as well ranks sixth in the spoken genre. Might as well and May as well show the same pattern with respect to the spoken genre of the COCA (3 July. 2021. Online https://corpus.byu.edu/coca). That is, both Might as well and May as well rank sixth in the spoken genre. It must be noted, however, that Might as well is favored over May as well. Specifically, the frequency of Might as well is 762 tokens, whereas that of May as well is 102 tokens. This in turn implies that Americans prefer using Might as well to using May as well in daily conversation. We thus conclude that Might as well is slightly different from May as well in its use and preference.

\section{B. The Genre Frequency of May as Well and Might as Well in the BNC}

We examine the genre frequency of May as well and Might as well in the BNC (3 July. 2021. Online https://corpus.byu.edu/bnc). We compare the results from the COCA (3 July. 2021. Online https://corpus.byu.edu/coca) and those from the BNC (3 July. 2021. Online https://corpus.byu.edu/bnc):

TABLE 2

GENRE FREQUENCY OF MAY AS WELL AND MIGHT AS WELL IN THE BNC

\begin{tabular}{|l|l|l|l|l|l|l|l|l|}
\hline Genre & ALL & SPOK & FIC & MAG & NEWS & $\begin{array}{l}\text { NON- } \\
\text { ACAD }\end{array}$ & ACAD \\
\hline $\begin{array}{l}\text { May as } \\
\text { well }\end{array}$ & 187 & 64 & 74 & 8 & 10 & 7 & 4 & 20 \\
\hline $\begin{array}{l}\text { Might as } \\
\text { well }\end{array}$ & 982 & 355 & 390 & 41 & 55 & 48 & 19 & 74 \\
\hline
\end{tabular}

An immediate question is "Which type is the preferable expression among the British?" Table 2 clearly shows that the type Might as well is preferred by the British. The overall frequency of May as well is 187 tokens, whereas that of Might as well is 982 tokens. This in turn suggests that Might as well may be preferred over May as well by the British. As alluded to in Table 1 and Table 2, Americans and the British show the same pattern with respect to the use of May as well and Might as well. That is, the type Might as well is preferred by Americans and the British.

We now examine the genre frequency of May as well and Might as well in the BNC (3 July. 2021. Online https://corpus.byu.edu/bnc). The question is, "In which genre is May as well the most frequently used?" Table 2 clearly indicates that May as well is the most widely used in the fiction genre. From this, it is clear that British writers most prefer May as well in their novels. It should be noted, however, that Might as well may be preferred over May as well by British writers. Specifically, the frequency of Might as well is five times higher than that of May as well. In this respect, Americans and the British share a commonality. That is, they prefer using Might as well to using May as well in the fiction genre. However, Americans and the British show a different pattern with respect to the genre frequency of May as well and Might as well. That is, Americans prefer May as well the most in the TV/movie genre, whereas the British most prefer the collocation in the fiction genre.

It is noteworthy that May as well is the second most preferred expression in the spoken genre. The difference between the frequency of May as well in the fiction genre and that of the spoken genre is 10 tokens. This clearly indicates that the British are fond of using the type May as well. A major point to note is that May as well ranks sixth in the spoken genre of the COCA (3 July. 2021. Online https://corpus.byu.edu/coca), whereas it ranks second in the spoken genre of the BNC (3 July. 2021. Online https://corpus.byu.edu/bnc). This may imply that the British prefer the type May as well more than Americans. A further point to note is that Might as well may be preferred over May as well by the British. The same applies to the COCA (3 July. 2021. Online https://corpus.byu.edu/coca). The type Might as well may be favored over May as well in the spoken genre of the COCA (3 July. 2021. Online https://corpus.byu.edu/coca). Thus, it is reasonable to assume that Americans and the British exhibit the same pattern with respect to the use of May as well and Might as well in the spoken genre.

May as well is the fourth most preferred collocation in the newspaper genre. The frequency of May as well in the newspaper genre is low compared with that of the fiction genre. In addition, the difference between the frequency of May as well in the newspaper genre and that of the spoken genre is 54 tokens. This in turn suggests that May as well is not as frequently used in British newspapers. Rather, Might as well instead of May as well is preferred by British journalists. The evidence comes from the fact that the frequency of May as well in the newspaper genre is 10 tokens, whereas that of might as well is 55 tokens.

Now let us consider the genre frequency of Might as well in the BNC (3 July. 2021. Online https://corpus.byu.edu/bnc). An immediate question is "In which genre is Might as well the most commonly used?" Table 2 clearly indicates that the type Might as well is the most widely used in the fiction genre. This indicates that the British most prefer Might as well in the fiction genre. It is worth pointing out that Might as well ranks second in the fiction genre of the COCA (3 July. 2021. Online https://corpus.byu.edu/coca), whereas it ranks first in the fiction genre of the BNC (3 July. 2021. Online https://corpus.byu.edu/bnc), hence almost the same pattern. This suggests that American and British writers prefer using the type Might as well in their novels. In addition, American and British writers prefer using the type Might as well to May as well in the fiction genre, thus showing the same pattern.

It is important to note that Might as well is the second most preferred collocation in the spoken genre. There is no significant difference between the frequency of Might as well in the fiction genre and that of the spoken genre. There is only a difference of 35 tokens between the two genres. It can thus be inferred that the British more frequently the type 
Might as well in daily conversation. More interestingly, Might as well ranks six in the spoken genre of the COCA (3 July. 2021. Online https://corpus.byu.edu/coca), whereas it ranks second in the spoken genre of the BNC (3 July. 2021. Online https://corpus.byu.edu/bnc). This may imply that the British prefer Might as well more than Americans. Thus, Americans and the British show a different pattern with respect to the genre use of Might as well. It should be pointed out that Might as well may be preferred over May as well by Americans and the British. The evidence stems from the fact that the frequency of Might as well is higher than that of May as well in the spoken genre of the COCA (3 July. 2021. Online https://corpus.byu.edu/coca) and BNC. Thus, Americans and the British show the same pattern with respect to their preference towards Might as well.

Finally, the frequency of Might as well in the newspaper genre is low compared with that in the fiction genre. There is a difference of 345 tokens between the frequency of Might as well in the newspaper genre and that of the fiction genre. This indicates that Might as well is not used as frequently in British newspapers. It should be emphasized, however, that Might as well may be favored over May as well in British newspapers.

\section{The Frequency of May as Well and Might as Well in the COHA}

Below, we examine the frequency of May as well and Might as well in the COHA (1820-2010 (3 July. 2021. Online. https://corpus.byu.edu/coha)).

TABLE 3

FREQUENCY OF MAY AS WELL AND MighT AS WELL IN THE COHA

\begin{tabular}{|l|l|l|}
\hline Year & Frequency of May as well & Frequency of Might as well \\
\hline 1820 & 51 & 63 \\
\hline 1830 & 121 & 124 \\
\hline 1840 & 120 & 148 \\
\hline 1850 & 179 & 190 \\
\hline 1860 & 174 & 229 \\
\hline 1870 & 179 & 289 \\
\hline 1880 & 193 & 282 \\
\hline 1890 & 161 & 244 \\
\hline 1900 & 124 & 335 \\
\hline 1910 & 237 & 434 \\
\hline 1920 & 123 & 439 \\
\hline 1930 & 118 & 637 \\
\hline 1940 & 120 & 606 \\
\hline 1950 & 110 & 696 \\
\hline 1960 & 94 & 632 \\
\hline 1970 & 70 & 518 \\
\hline 1980 & 62 & 458 \\
\hline 1990 & 66 & 554 \\
\hline 2000 & 82 & 580 \\
\hline $\mathbf{2 0 1 0}$ & 75 & 535 \\
\hline $\mathbf{A l l}$ & 2,459 & 7,993 \\
\hline
\end{tabular}

An immediate question is "Which type was preferred by Americans from 1820 to 2010?" Table 3 clearly indicates that the frequency of Might as well is three times higher than that of May as well. This shows that Might as well may be preferred over May as well by Americans.

There was an increase of 70 tokens in the frequency of May as well from 1820 to 1830 . After this period, there were slight fluctuations in the frequency of May as well from 1840 to 1870 . Subsequently, there was a steady decline in the frequency of May as well from 1880 to 1900. Specifically, there was a decline of 69 tokens from 1880 to 1900. Interestingly, there was a sudden increase in the frequency of May as well in 1910. This translated to an increase of 113 tokens that year. After this time period, there was a sudden decrease in the frequency of May as well, followed by its gradual decline in the frequency from 1940 to 1980. There was a decrease of 58 tokens. After this period, there were slight fluctuations in the frequency of May as well from 1990 to 2010. A major point to note is that May as well had the lowest frequency (51 tokens) in 1820. This suggests that the collocation was the most undesired type in 1820 . On the other hand, May as well reached a peak in 1910. This implies that it was the most preferable expression among Americans in 1910. Finally, it should be noted that Might as well was always preferred over May as well by Americans from 1820 to 2010.

There was a steady increase in the frequency of Might as well from 1820 to 1870. Specifically, there was a rise of 226 tokens from 1820 to 1870 . After this period, there was a sudden decrease in the frequency of Might as well in 1890 (decline of 45 tokens). Interestingly, there was a gradual rise in the frequency of Might as well, up 302 tokens, from 1900 to 1930. There were also fluctuations in the frequency of Might as well from 1940 to 1960. Furthermore, the frequency of Might as well decreased suddenly in 1970. Subsequently, there was a gradual increase in the frequency of Might as well from 1980 to 2000. This translated to an increase of 122 tokens. However, there was a decline of 45 tokens in 2010. Perhaps most interestingly, Might as well had the lowest frequency in 1820, which suggests that it was the most undesired type in 1820. On the other hand, Might as well reached a peak in 1950, which indicates that it was 
the most preferable collocation among Americans in 1950. Finally, it is significant to note that during the entire period (1820-2010), Might as well was always favored over May as well in America.

\section{The Collocations of MaY AS Well AND Might aS WELL IN THE COCA AND BNC}

\section{A. The Collocations of May as Well and Might as Well in the COCA}

In the following, we consider the collocation of May as well in the COCA (3 July. 2021. Online https://corpus.byu.edu/coca):

TABLE 4

COLLOCATION OF MAY AS WELL IN THE COCA

\begin{tabular}{|l|l|l|}
\hline NUMBER & COLLOCATION OF MAY AS WELL & FREQUENCY \\
\hline $\mathbf{1}$ & May as well go & 74 \\
\hline $\mathbf{2}$ & May as well get & 64 \\
\hline $\mathbf{3}$ & May as well give & 32 \\
\hline $\mathbf{5}$ & May as well take & 31 \\
\hline $\mathbf{6}$ & May as well try & 31 \\
\hline $\mathbf{7}$ & May as well make & 26 \\
\hline $\mathbf{8}$ & May as well start & 23 \\
\hline 10 & May as well tell & 23 \\
\hline 11 & May as well put & 22 \\
\hline 12 & May as well say & 21 \\
\hline 13 & May as well call & 20 \\
\hline 14 & May as well use & 20 \\
\hline 15 & May as well know & 18 \\
\hline 16 & May as well come & 16 \\
\hline 17 & May as well enjoy & 15 \\
\hline 18 & May as well stay & 15 \\
\hline 19 & May as well ask & 12 \\
\hline 20 & May as well see & 12 \\
\hline
\end{tabular}

An important question is "Which verb is the most preferred by Americans?" Table 4 clearly indicates that the verb go is the most frequently used along with the type May as well. This demonstrates that the collocation May as well go is the most preferable among Americans. As alluded to in Table 4, May as well go is the most preferred by Americans, followed by May as well get, May as well give, May as well take, May as well try, May as well make, and May as well start, in descending order. It is interesting to point out that the collocation May as well get is the second most preferred in America. There is no significant difference between the frequency of the collocation May as well go and that of May as well get (74 tokens vs. 64 tokens). This in turn implies that Americans most prefer the collocation May as well go and like using the collocation May as well get. It is worth noting that the everyday expression May as well try is the fifth most preferred in America.

We now present the visualization of the collocation of May as well: 


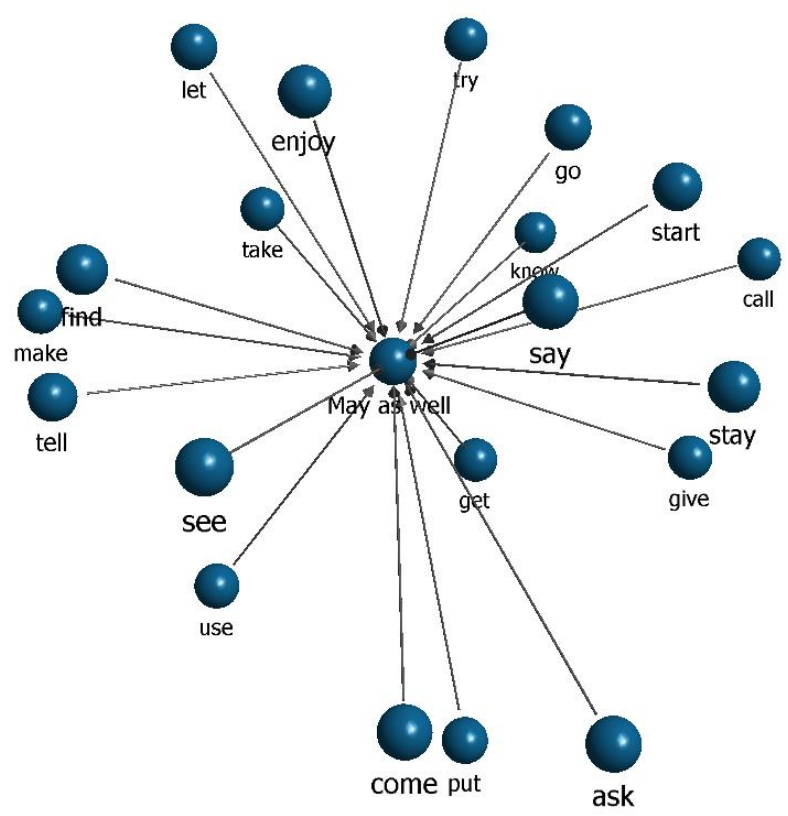

Figure 1. Visualization of May as well and Verbs in the COCA

As shown in Figure 1, we visualized the collocation of May as well in the top 20. A 3D visualization of the collocation of May as well was performed. As indicated in Figure 1, each verb is linked to the type May as well. This indicates that each verb has a collocation relationship with the type May as well.

Below, we examine the collocation of Might as well in the COCA (3 July. 2021. Online https://corpus.byu.edu/coca).

TABLE 5

COLloc ATION OF Might AS WELl IN THE COCA

\begin{tabular}{|l|l|l|}
\hline Number & Collocation of May as well & Frequency \\
\hline $\mathbf{1}$ & Might as well get & 518 \\
\hline $\mathbf{2}$ & Might as well go & 441 \\
\hline $\mathbf{3}$ & Might as well make & 197 \\
\hline $\mathbf{4}$ & Might as well take & 181 \\
\hline $\mathbf{5}$ & Might as well give & 176 \\
\hline $\mathbf{6}$ & Might as well start & 158 \\
\hline $\mathbf{7}$ & Might as well try & 150 \\
\hline $\mathbf{8}$ & Might as well say & 132 \\
\hline 10 & Might as well tell & 124 \\
\hline 11 & Might as well put & 113 \\
\hline 12 & Might as well come & 80 \\
\hline 13 & Might as well use & 80 \\
\hline 14 & Might as well enjoy & 79 \\
\hline 15 & Might as well call & 74 \\
\hline \hline 16 & Might as well stay & 72 \\
\hline 17 & Might as well ask & 68 \\
\hline \hline 18 & Might as well let & 68 \\
\hline 19 & Might as well throw & 68 \\
\hline \hline 20 & Might as well keep & 62 \\
\hline
\end{tabular}

An immediate question is "Which verb is the most frequently used in the COCA (3 July. 2021. Online https://corpus.byu.edu/coca)?" Table 5 clearly shows that the collocation Might as well get is the most widely used in America. This suggests that Might as well get is the most preferable among Americans. As illustrated in Table 5, Might as well get is the most preferred by Americans, followed by Might as well go, Might as well make, Might as well take, Might as well give, Might as well start, Might as well try, Might as well say, and Might as well tell, in descending order. It should be pointed out that the collocation of Might as well may be preferred over that of May as well by Americans. This stems from the fact that the frequency of the collocation of Might as well is higher than that of May as well. The collocation May as well get is also the second most preferred in America, whereas Might as well get is the most preferred in America. On the other hand, the collocation May as well go is the most preferred in America, whereas 
Might as well go is the second most preferred in America. This in turn indicates that the collocation of May as well is slightly different from that of Might as well. It is interesting to point out that the collocation Might as well say ranks eighth in the top 20.

Below is a visualization of the collocations of Might as well and May as well.

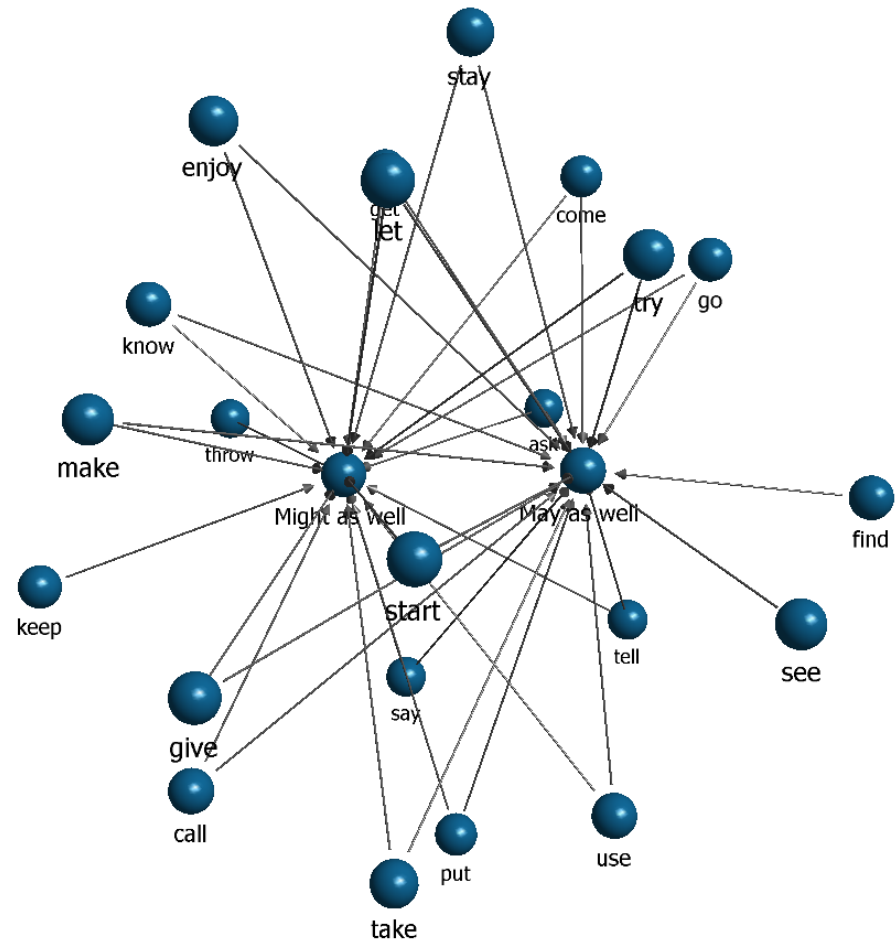

Figure 2. Visualization of the collocations of Might as well and May as well

As illustrated in Figure 2, we visualized the collocations of Might as well and May as well. Each verb is linked to the types Might as well and May as well. As indicated in Figure 2, particular verbs are linked to Might as well and May as well twice. This indicates that these verbs are a collocation of Might as well and May as well. The software NetMiner captures these collocations of Might as well and May as well.

\section{B. The Collocations of May as Well and Might as Well in the BNC}

In this section, we aim to examine the collocations of May as well and Might as well in the BNC (3 July. 2021. Online https://corpus.byu.edu/bnc). Table 6 indicates the frequency of the collocation of May as well in the top 20.

TABLE 6

COLlocation OF MAY AS WELl IN THE BNC

\begin{tabular}{|l|l|l|}
\hline Number & Collocation of May well and verbs & Frequency \\
\hline 1 & May as well go & 11 \\
\hline $\mathbf{2}$ & May as well tell & 10 \\
\hline $\mathbf{3}$ & May as well get & 10 \\
\hline $\mathbf{5}$ & May as well make & 7 \\
\hline $\mathbf{6}$ & May as well use & 6 \\
\hline $\mathbf{7}$ & May as well sit & 5 \\
\hline $\mathbf{8}$ & May as well give & 5 \\
\hline $\mathbf{9}$ & May as well call & 4 \\
\hline 10 & May as well start & 4 \\
\hline 12 & May as well take & 4 \\
\hline 13 & May as well stay & 3 \\
\hline \hline 14 & May as well accept & 3 \\
\hline 15 & May as well say & 3 \\
\hline \hline 16 & May as well let & 3 \\
\hline 17 & May as well forget & 3 \\
\hline 18 & May as well ask & 3 \\
\hline 19 & May as well buy & 2 \\
\hline 20 & May as well come & 2 \\
\hline
\end{tabular}


An important question is "Which verb is the most commonly used along with May as well in the UK?" Table 6 clearly shows that the collocation May as well go is the most widely used in the UK. This suggests that May as well go is the most preferable collocation among the British. As alluded to in Table 6, the collocation May as well go is the most preferred by the British, followed by May as well tell (May as well get), May as well make, May as well use, May as well sit (May as well give), and May as well call, in descending order. It is interesting to point out that both Americans and the British most prefer the collocation May as well go. Moreover, May as well get is the second most preferred in America, whereas it is the third most preferred in the UK. From this, it is evident that Americans and the British show almost the same pattern with respect to the use of the collocation May as well. It should be noted, however, that the collocation May as well tell ranks eighth in the COCA (3 July. 2021. Online https://corpus.byu.edu/coca), whereas it ranks second the BNC (3 July. 2021. Online https://corpus.byu.edu/bnc), which in turn suggests that Americans and the British show a different pattern with respect to the use of the collocation May as well tell. More interestingly, the collocation May as well make ranks sixth in the COCA (3 July. 2021. Online https://corpus.byu.edu/coca), whereas it ranks fourth in the BNC (3 July. 2021. Online https://corpus.byu.edu/bnc), which suggests that Americans and the British show a similar pattern with respect to the use of the collocation May as well make.

Now let us observe the visualization of the collocation of May as well in the BNC (3 July. 2021. Online https://corpus.byu.edu/bnc):

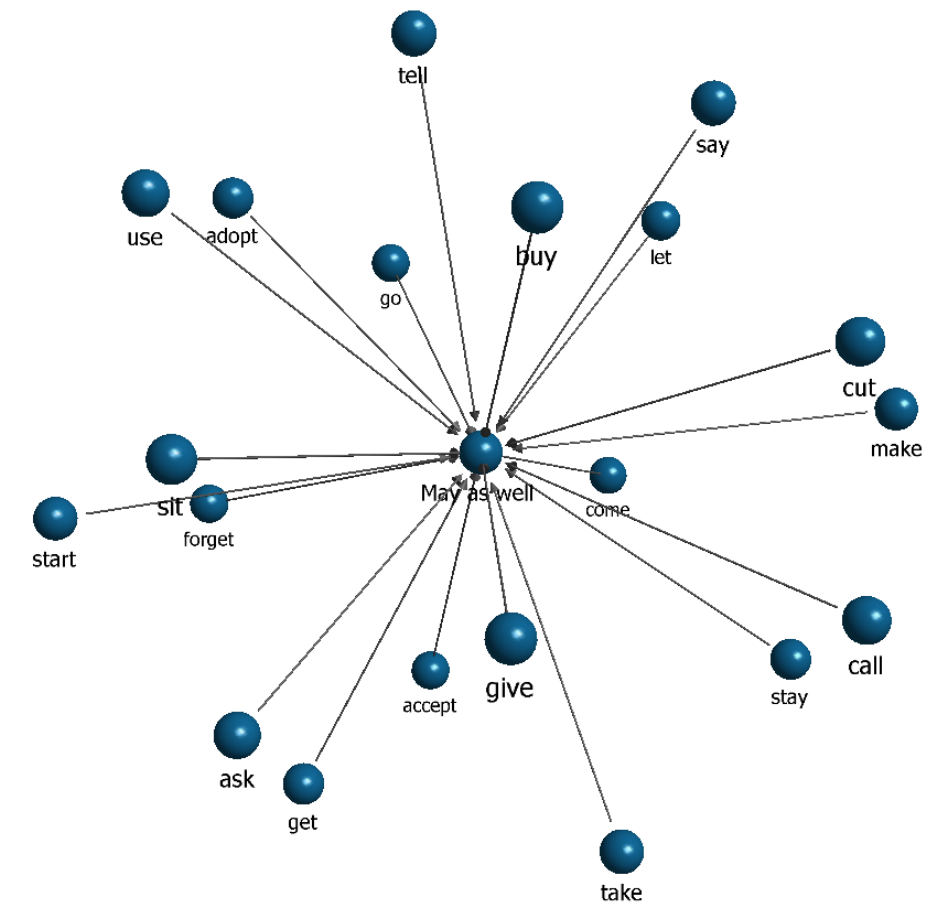

Figure 3. Visualization of the collocation of May as well in the BNC

As illustrated in Figure 3, we visualized the collocation of May as well in the top 20. Each verb is linked to the type May as well and it is the collocation of the type May as well in the BNC (3 July. 2021. Online https://corpus.byu.edu/bnc). A 3D visualization of the collocation of May as well was performed.

In the following, we consider the collocation of Might as well in the BNC (3 July. 2021. Online https://corpus.byu.edu/bnc): 
TABLE 7.

COLLOCATION OF Might AS WELL IN THE BNC

\begin{tabular}{|l|l|l|l|}
\hline Number & Collocation of May as well & Frequency \\
\hline 1 & Might as well go & 75 \\
\hline 2 & Might as well get & 65 \\
\hline 3 & Might as well make & 19 \\
\hline 4 & Might as well take & 19 \\
\hline 5 & Might as well give & 18 \\
\hline 6 & Might as well put & 17 \\
\hline 7 & Might as well try & 16 \\
\hline $\mathbf{8}$ & Might as well say & 15 \\
\hline $\mathbf{1 0}$ & Might as well come & 13 \\
\hline 10 & Might as well let & 11 \\
\hline 11 & Might as well buy & 11 \\
\hline 12 & Might as well tell & 11 \\
\hline 13 & Might as well ask & 10 \\
\hline 15 & Might as well stay & 9 \\
\hline 16 & Might as well use & 8 \\
\hline 17 & Might as well leave & 7 \\
\hline 18 & Might as well know & 7 \\
\hline 19 & Might as well enjoy & 7 \\
\hline 20 & Might as well wait & 7 \\
\hline
\end{tabular}

Table 7 indicates the frequency of the collocation of Might as well in the top 20. An important question is "Which verb is the most frequently used along with Might as well in the UK?" Table 7 clearly shows that the verb go is the most widely used along with Might as well. This implies that the collocation Might as well go is the most preferred by the British. As illustrated in Table 7, Might as well go is the most preferable collocation among the British, followed by Might as well get, Might as well make (Might as well take), Might as well give, Might as well put, Might as well try, and Might as well say, in descending order. It is interesting to note that Americans most prefer Might as well get, whereas the British most prefer Might as well go. On the other hand, it is worth noting that Might as well go is the second most preferred in America, whereas Might as well get is the second most preferred in the UK. This indicates that Americans and the British show a similar pattern with respect to the collocation of Might as well. Additionally, it should be pointed out that the collocations Might as well make and Might as well take rank third in the BNC (3 July. 2021. Online https://corpus.byu.edu/bnc), whereas Might as well make ranks third in the COCA (3 July. 2021. Online https://corpus.byu.edu/coca) and Might as well take ranks fourth in the COCA (3 July. 2021. Online https://corpus.byu.edu/coca). From this, it is evident that Americans and the British show almost the same pattern with respect to the collocations Might as well make and Might as well take. With respect to Might as well give, the expression ranks fifth in America and the UK, hence the same pattern.

We now compare the collocations of May as well and Might as well in the BNC (3 July. 2021. Online https://corpus.byu.edu/bnc). Note that May as well go and Might as well go rank first in the UK, respectively. On the other hand, May as well get ranks third in the BNC (3 July. 2021. Online https://corpus.byu.edu/bnc), whereas Might as well get ranks second. May as well make is the fourth most preferred in the UK, whereas Might as well make is the third most preferred. Clearly, the British show a similar pattern with respect to the collocations of May as well and Might as well. It should be noted, however, that May as well take ranks tenth in the BNC (3 July. 2021. Online https://corpus.byu.edu/bnc), whereas Might as well take ranks fourth, thus revealing a different pattern.

Finally, we examine the visualization of the collocations of May as well and Might as well in the BNC (3 July. 2021. Online https://corpus.byu.edu/bnc): 


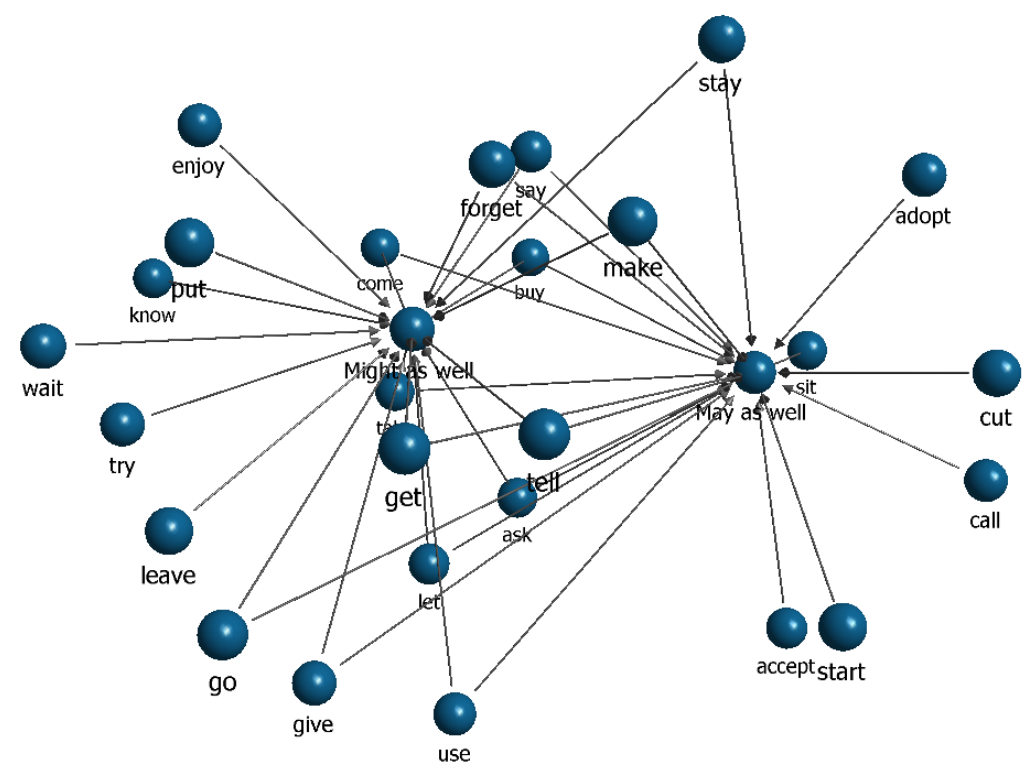

Figure 4. Visualization of the collocations of May as well and Might as well in the BNC

As indicated in Figure 4, a 3D visualization of the collocations May as well and Might as well was performed. Each verb is linked to May as well or Might as well. Many verbs are linked to both May as well and Might as well twice. This indicates that these verbs are a collocation of both May as well and Might as well. However, many verbs are not linked to both May as well and Might as well twice. This suggests that these verbs are not a collocation of both May as well and Might as well. As shown in Figure 4, there are several verbs that are linked to May as well, but not linked to Might as well. Conversely, there are several verbs that are linked to Might as well, but not linked to May as well. This in turn implies that Might as well is slightly different from May as well in its use.

\section{CONCLUSION}

In summary, we have compared the collocations May as well and Might as well and provided a frequency analysis of each in the COCA (3 July. 2021. Online https://corpus.byu.edu/coca), BNC (3 July. 2021. Online https://corpus.byu.edu/bnc), and COHA (3 July. 2021. Online. https://corpus.byu.edu/coha). In Section 2.1, we have argued that just as in the case of May as well, Might as well is the most widely used in the TV/movie genre of eight genres. It can thus be inferred that American celebrities prefer using Might as well in the TV/movie genre. In Section 2.2, we have contended that May as well and Might as well are the most widely used in the fiction genre of the BNC (3 July. 2021. Online https://corpus.byu.edu/bnc). From this, it is clear that British writers most prefer May as well and Might as well. In Section 2.3, we have maintained that the frequency of Might as well is three times higher than that of May as well. This indicates that Might as well may be preferred over May as well by Americans. We have also maintained that May as well reached a peak in 1910. This implies that the collocation was the most preferable among Americans in 1910. On the other hand, we have argued that Might as well reached a peak in 1950, which indicates that it was the most preferable among Americans that year. In Section 3.1, we have argued that May as well go is the most preferred by Americans, followed by May as well get, May as well give, May as well take, May as well try, May as well make, and May as well start, in descending order. On the other hand, we have further argued that Might as well get is the most preferred by Americans, followed by Might as well go, Might as well make, Might as well take, Might as well give, Might as well start, Might as well try, Might as well say, and Might as well tell, in descending order. In Section 3.2 , we have maintained that the collocation May as well go is the most preferred by the British, followed by May as well tell (May as well get), May as well make, May as well use, May as well sit (May as well give), and May as well call, in descending order. We have also maintained that Might as well go is the most preferable among the British, followed by Might as well get, Might as well make (Might as well take), Might as well give, Might as well put, Might as well try, and Might as well say, in descending order. Finally, we have contended that Might as well is slightly different from May as well in its use. 


\section{REFERENCES}

[1] British National Corpus (BNC). 3 July. 2021. Online https://corpus.byu.edu/bnc.

[2] Corpus of Contemporary American English (COCA). 3 July. 2021. Online https://corpus.byu.edu/coca.

[3] Corpus of Historical American English (COHA). 3 July. 2021. Online. https://corpus.byu.edu/coha.

[4] Murphy, R. (2016). Grammar in Use. Cambridge University Press. Singapore.

[5] Murphy, R. (2019). English Grammar in Use. Cambridge University Press. New York.

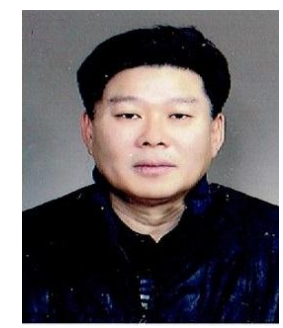

Namkil Kang, he was born in Chungbuk, South Korea on 27, August, 1964. He received a BA degree (English Language and Literature) at Chungbuk National University in South Korea in 1988. He received an MA degree (English Linguistics) at Sogang University in South Korea in 1990. He received an MPhil degree (Linguistics) at the University of Oxford in 1998. Finally, he received a Ph.D. degree (Linguistics) at the University of Oxford in 2000.

He has been with Far East University in South Korea since 2002. He is a professor at Far East University in South Korea. He is working on syntax, corpus linguistics, and English education at this moment. He has published about 75 articles and three books. He is a recent ex-chairman of the Joongwon Linguistic Society of South Korea and a vice-chairman of the Jungang English Language and Literature Association of South Korea. 